\title{
Tuning Excited-State Electron Transfer from an Adiabatic to Nonadiabatic Type in Donor-Bridge-Acceptor Systems and the Associated Energy-Transfer Process
}

\author{
Kew-Yu Chen, ${ }^{\dagger}, \star$ Cheng-Chih Hsieh,${ }^{\dagger}$ Yi-Ming Cheng, ${ }^{\dagger}$ Chin-Hung Lai, ${ }^{\dagger}$ Pi-Tai Chou,,${ }^{*} \dagger$ and \\ Tahsin J. Chow*; \\ Department of Chemistry, National Taiwan University, Taipei, 106, Taiwan, R.O.C., Institute of Chemistry, \\ Academia Sinica, Taipei, 115, Taiwan, R.O.C
}

Received: May 18, 2006; In Final Form: July 24, 2006

\begin{abstract}
Through design and synthesis of a new series of dyads I-III composed of 2,3-dimethoxynaphthalene as an electron donor (D) and 2,3-dicyanonaphthalene as an acceptor (A) bridged by $n$-norbornadiene $(n=1-3)$ we demonstrate an excellent prototype to switch the excited-state electron-transfer dynamics from an adiabatic to a nonadiabatic process. I reveals a remarkable excitonic effect and undergoes an adiabatic type of electron transfer (ET), resulting in a unique charge-transfer emission, of which the peak wavelength exhibits strong solvatochromism. Conversely, upon exciting the donor moiety, a fast D $\rightarrow$ A energy transfer takes place for II ( $\sim 3 \mathrm{ps})$ and III ( $\leq 30 \mathrm{ps})$, followed by a nonadiabatic type, weak coupled electron transfer with a relatively slow ET rate, giving rise to dual emission in polar solvents. Further detailed temperature-dependent studies of the ET rate deduced reaction barriers of $2.7 \mathrm{kcal} / \mathrm{mol}$ (for II) and $1.3 \mathrm{kcal} / \mathrm{mol}$ (for III) in diethyl ether and $\mathrm{CH}_{2} \mathrm{Cl}_{2}$, respectively. The results lead to a deduction of the reaction free energy and reorganization energy for both II (in diethyl ether) and III (in $\mathrm{CH}_{2} \mathrm{Cl}_{2}$ ). Theoretical (for I) and experimental (for II and III) approaches estimate the electronic coupling to be $860,21.9$, and $3.2 \mathrm{~cm}^{-1}$ for I, II, and III, respectively, supporting the adiabatic versus nonadiabatic switching mechanism.
\end{abstract}

\section{Introduction}

Owing to its fundamental importance and prospect in applications, excited-state electron transfer has received much attention, and the corresponding results have been collected into numerous book volumes and literature. ${ }^{1}$ Among the various relevant research directions, one fundamental issue lies in the differentiation between adiabatic and nonadiabatic types of electron transfer. A rather strong coupling between electron donor (D) and acceptor (A) may result in a great mixing between two potential energy surfaces such that the electron transfer is essentially along the same potential energy surface in the excited state. Such an adiabatic process is commonly referred to as the optical electron transfer. On the other hand, weak coupling leads to a small interaction of $\ll k T(298 \mathrm{~K})$ between the potential surfaces of reactant (D) and product (A), resulting in an appreciable barrier along the electron-transfer process. This diabatic process is commonly defined as the photoinduced electron transfer (PET). Optical electron-transfer process responses concurrent with the optical excitation and the observed relaxation dynamics are usually manifested by the solvent relaxation due to a large alternation in the dipolar vector, giving rise to the emission solvatochromism. ${ }^{2}$ Conversely, the relatively slow rate of PET may compete with other deactivation pathways such as fluorescence, internal conversion, intersystem crossing, etc., such that dual emission, consisting of the donor fluorescence (assuming only donor being excited) and $\mathrm{D}^{+} \mathrm{A}^{-}$chargetransfer emission, may be resolved. The emission intensity for the latter case is normally weak and in most cases is irresolvable

* Corresponding author. E-mail: chop@ntu.edu.tw. Tel: +886-227898552. Fax: +886-2-27884179.

National Taiwan University.

$\div$ Academia Sinica. due to its forbidden transition in character versus the neutral ground state. Numerous studies have been focusing on the D/A dyads linked by either a rigid or flexible framework to study the associated PET processes, ${ }^{3}$ among which key issues regarding through bond, through space, or structural tuning parameters have been thoroughly examined to gain detailed insights into the associated mechanism/theory. In yet another approach, studies have also been focusing on the optical electron transfer with an aim to probe the solvent relaxation dynamics. ${ }^{4}$ The combination of these two stimulates us to propose the rational design of a series of simple $\mathrm{D}-$ bridge $-\mathrm{A}$ systems so that the switching from adiabatic (optical) to nonadiabatic (photoinduced) electron transfer can be systematically fine-tuned. To achieve this goal, we report herein the design of a series of $D$ (2,3-dimethoxynaphthalene)-B (bridge)-A (2,3-dicyanonaphthalene) dyads, in which the adiabatic vs nonadiabatic electron transfer, fine-tuned by the bridge units, is manifested by the remarkable changes in both spectroscopic and dynamic properties. Comprehensive D/A coupling properties have been examined via both experimental and theoretical approaches. The results render a prototypical model to facilitate the studies of adiabatic vs nonadiabatic electron-transfer reaction at both theoretical and experimental levels.

\section{Experimental Section}

Synthesis. The new series of D/A dyads I-III, where D and A represent 2,3-dimethoxynaphthalene (OMe-NP) and 2,3dicyanonaphthalenme (CN-NP), respectively, were synthesized according to a synthetic route depicted in Scheme 1. The norbornadiene (NBD) dimer and trimer were prepared through a coupling reaction of norbornadiene (NBD) catalyzed by $\mathrm{Co}_{2}-$ $(\mathrm{CO})_{6}\left(\mathrm{PPh}_{3}\right)_{2} \cdot{ }^{5}$ General procedures for processes $1-3$ specified in Scheme 1 are described below. 


\section{SCHEME 1}

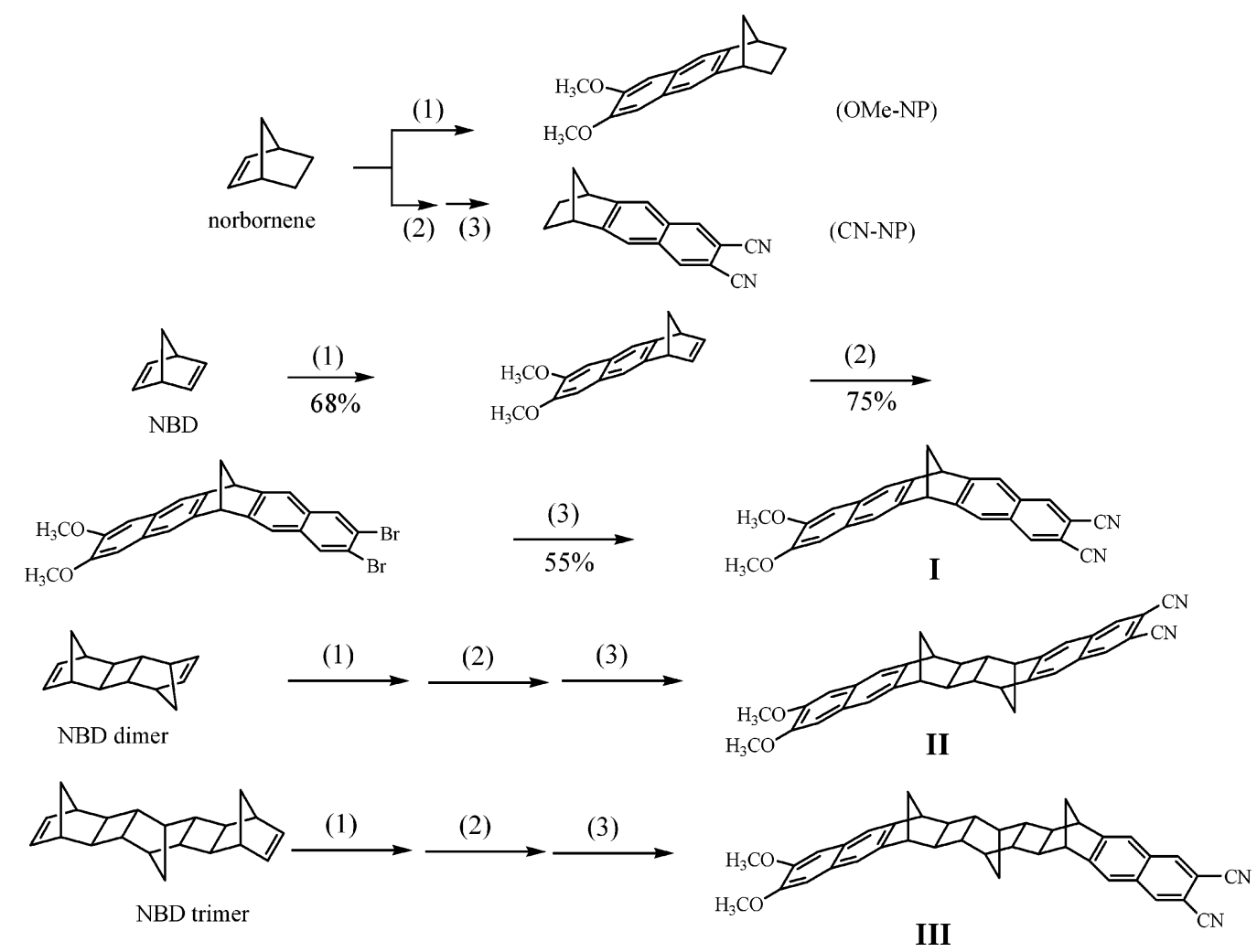

Procedure 1. A mixture of $\alpha, \alpha, \alpha^{\prime}, \alpha^{\prime}$-tetrabromo-4,5-dimethoxy$o$-xylene. ${ }^{6}(0.50 \mathrm{~g}, 1.00 \mathrm{mmol})$, dienophile (NBD, NBD dimer, ND trimer) $(1.00 \mathrm{mmol})$, sodium iodide $(0.90 \mathrm{~g}, 6.0 \mathrm{mmol})$, and dry DMF $(15 \mathrm{~mL})$ was stirred at $65{ }^{\circ} \mathrm{C}$ for $24 \mathrm{~h}$. The reaction mixture was poured into cold water $(70 \mathrm{~mL})$ containing sodium bisulfite $(1.00 \mathrm{~g})$. The yellow precipitate was purified by chromatography ( silica gel column, hexane:ethyl acetate $=$ $7: 1)$ and finally by recrystallization.

Procedure 2. A mixture of $\alpha, \alpha, \alpha^{\prime}, \alpha^{\prime}-4,5$-hexabromo-o-xylene (2.5 g, $4.3 \mathrm{mmol})$, dimethoxy derivative $(4.3 \mathrm{mmol})$, sodium iodide $(4.5 \mathrm{~g}, 30 \mathrm{mmol})$, and dry DMF $(50 \mathrm{~mL})$ was stirred at $65^{\circ} \mathrm{C}$ for $24 \mathrm{~h}$. The reaction mixture was poured into cold water $(350 \mathrm{~mL})$ containing sodium bisulfite $(5.0 \mathrm{~g})$. The yellow precipitate was purified by chromatography (silica gel column, hexane:ethyl acetate $=6: 1$ ) and finally by recrystallization.

Procedure 3. A mixture of dibromo derivative (1.00 $\mathrm{mmol})$, cuprous cyanide $(0.40 \mathrm{~g}, 4.0 \mathrm{mmol})$, sodium iodide $(0.10 \mathrm{mmol})$, and dry DMF $(15 \mathrm{~mL})$ was refluxed for $48 \mathrm{~h}$ under nitrogen atmosphere. Then the reaction mixture was poured into a 15 wt $\%$ aqueous ammonia solution. The yellow precipitate was filtered off, washed with ammonia solution and water, and vacuum-dried. Chromatographic purification (silica gel column, hexane:ethyl acetate $=3: 1$ ) was followed by recrystallization to obtain compounds I-III. Detailed characterization of I-III is elaborated in the Supporting Information.

Measurements. Cyclic voltammetry (CV) measurements were performed using a BAS $100 \mathrm{~B} / \mathrm{W}$ electrochemical analyzer. The oxidation and reduction measurements were recorded, respectively, in anhydrous $\mathrm{CH}_{2} \mathrm{Cl}_{2}$ and anhydrous THF solution containing $0.1 \mathrm{M} \mathrm{TBAPF}_{6}$ as the supporting electrolyte, at the scan rate of $100 \mathrm{mV} \mathrm{s}^{-1}$. The potentials were measured against a $\mathrm{Ag} / \mathrm{Ag}^{+}\left(0.01 \mathrm{M} \mathrm{AgNO}_{3}\right)$ reference electrode with a ferrocene and ferrocenium couple as the internal standard. Steady-state absorption and emission spectra were recorded by a Hitachi (U3310) spectrophotometer and an Edinburgh (FS920) fluorometer, respectively. Pico- and nanosecond lifetime measurements were performed using a time-correlated single photon counting technique and a femtosecond optically gated system, respectively, which have been described in previous reports. ${ }^{7}$ For both pico- and femtosecond time-resolved measurements, the polarization of the pump laser was set at the magic angle $\left(54.7^{\circ}\right)$ with respect to that of the probe laser (or detecting system) to eliminate the fluorescence anisotropy. A variable temperature unit (Specac, P/N 21525) was used to carry out the temperaturedependent studies, for which a range of temperatures from 300 to $77 \mathrm{~K}$ can be achieved with an accuracy of $\pm 0.2{ }^{\circ} \mathrm{C}$.

Theoretical Approach. The dipole moment of the excited state is calculated by TDB3LYP/6-31G* based upon B3LYP/ 6-31G* geometry. ${ }^{8,9}$ According to Hellmann-Feynman theory, the dipole moment is the analytic derivative of the energy of the excited state with respect to an applied electric field. We thus calculate the excitation energy and ground-state energy upon applying the 0.001 au electric field from six directions $(x,-x, y,-y, z,-z)$. The excited-state energy in each direction is calculated to be the excitation energy plus the ground-state energy. Taking a numerical derivative as shown in eq 1 , we can obtain each direction of the excited-state dipole moment.

$$
\mu(x)=\frac{E(x)-E(-x)}{F(x)-F(-x)}
$$

where $E(x)$ is the excited-state energy in the $x$ direction and $F(x)$ is the applied electric field strength in the $x$ direction. The calculations were carried out using Gaussian03. ${ }^{10}$

\section{Results and Discussion}

3.1. Optical Electron Transfer in I. Figure 1 depicts the absorption spectra of OMe-NP, CN-NP (see Scheme 1), and I in $\mathrm{CH}_{2} \mathrm{Cl}_{2}$. Though composed of both OMe-NP and CN-NP linked by norbornene, I's absorption spectral feature is com- 


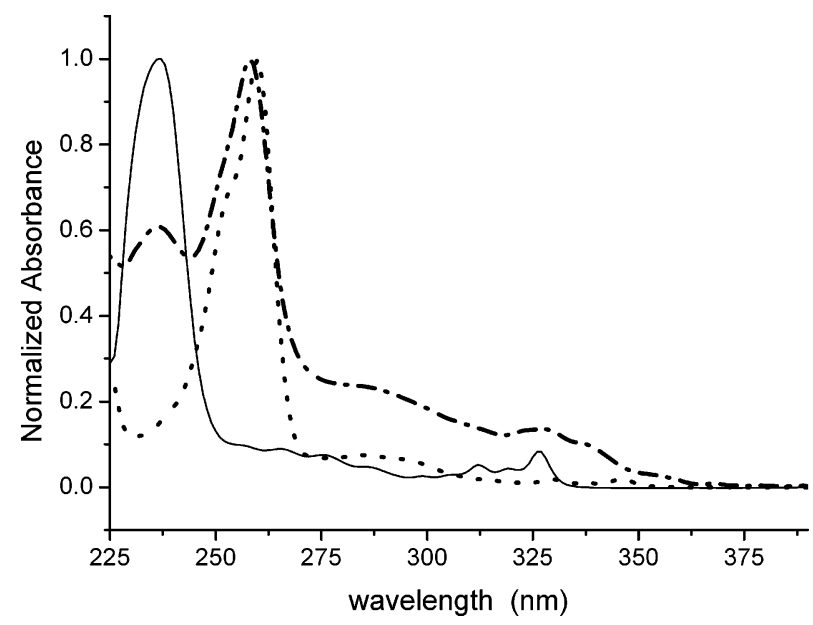

Figure 1. Absorption spectra of OMe-NP (-), CN-NP (- - -), and I $(--)$ in $\mathrm{CH}_{2} \mathrm{Cl}_{2}$.

pletely different from that of the sum of the two individual chromophores, i.e., OMe-NP and CN-NP. This is promptly viewed via the new spectral features of $\mathbf{I}$ in the region of 330$360 \mathrm{~nm}$, which do not appear in the spectra of either OMe-NP or CN-NP. The remarkable difference between $\mathbf{I}$ and OMe-NP (or CN-NP) was also revealed in the emission spectra. In $\mathrm{CH}_{2}-$ $\mathrm{Cl}_{2}$, OMe-NP and $\mathrm{CN}-\mathrm{NP}$ exhibited a strong emission with the peak wavelengths at 330 and $365 \mathrm{~nm}$, respectively. In comparison, $\mathbf{I}$ in $\mathrm{CH}_{2} \mathrm{Cl}_{2}$ exhibited a drastically red-shifted fluorescence maximized at $450 \mathrm{~nm}$. Both absorption and emission spectra lead us to conclude that there exists a strong coupling between OMe-NP and CN-NP chromophores in I. This absorption phenomenon is reminiscent of a two-bond (bicyclo[2.2.1]heptane) bridged naphthalene, ${ }^{11}$ in which the resonance (molecular exciton) splitting of the naphthalene ${ }^{1} \mathrm{~A}_{\mathrm{g}} \rightarrow 2^{1} \mathrm{~B}_{3 \mathrm{u}}$ takes place due to the through-space orbital overlap between two naphthalenes. As a result, a significantly different absorption profile was observed with respect to that of the single naphthalene unit.

For the case of $\mathbf{I}$, in addition to the excitonic interaction, the two nonequivalent moieties, strategically designed as electron donor (OMe-NP) and acceptor (CN-NP), make the electron transfer facile due to the strong OMe-NP/CN-NP interaction. This viewpoint can be firmly supported by the solvent-polaritydependent emission spectra depicted in Figure 2, in which the emission of I exhibited strong solvent-polarity dependence, being shifted from $380 \mathrm{~nm}$ in cyclohexane to $510 \mathrm{~nm}$ in $\mathrm{CH}_{3}$ $\mathrm{CN}$. That the entire emission originates from a common groundstate species is ascertained by the same fluorescence excitation spectra throughout the monitored emission wavelengths of 400$600 \mathrm{~nm}$, which are also effectively identical with the absorption spectrum. In comparison, the emission of OMe-NP (or $\mathrm{CN}$ NP) only revealed slight solvent-polarity independence, being shifted from $329 \mathrm{~nm}$ (in $\mathrm{C}_{6} \mathrm{H}_{12}$ ) to $330 \mathrm{~nm}$ (in $\mathrm{CH}_{3} \mathrm{CN}$ ) and $361 \mathrm{~nm}$ (in $\mathrm{C}_{6} \mathrm{H}_{12}$ ) to $365 \mathrm{~nm}$ (in $\mathrm{CH}_{3} \mathrm{CN}$ ) for OMe-NP and $\mathrm{CN}-\mathrm{NP}$, respectively. The results for $\mathbf{I}$ can be rationalized by the $\mathrm{S}_{0} \rightarrow \mathrm{S}_{1}$ absorption manifested by a simultaneous electrontransfer character incorporating electron donor (OMe-NP) and acceptor $(\mathrm{CN}-\mathrm{NP})$, resulting in large dipolar changes in either magnitude or orientation. The nonequilibrated solvated configuration is then subject to solvent relaxation and reaches an equilibrated solvation configuration. As shown in the inset in Figure 2, a Lippert plot for the emission peak frequency versus the solvent-polarity parameter function $\Delta f(=\epsilon-1 / 2 \epsilon+1, \epsilon$ being the static dielectric constant of the solvent) rendered a sufficiently straight line, and a slope as large as $-25500 \pm 750$

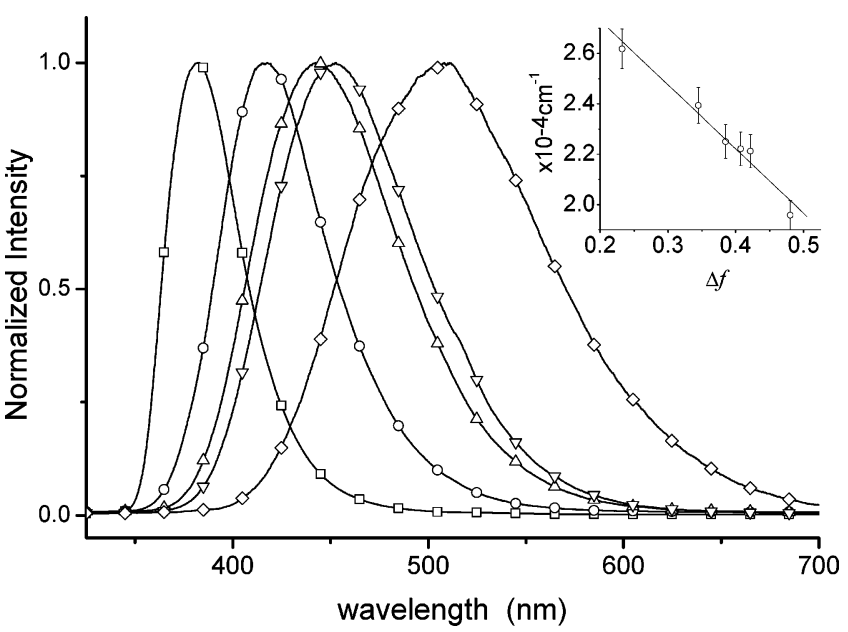

Figure 2. Emission spectra of $\mathbf{I}$ in $(\square)$ cyclohexane, $(O)$ ethyl ether, $(\triangle)$ ethyl acetate, $(\nabla)$ dichloromethane, and $(\diamond)$ acetonitrile. Inset: Lippert's plot of $\mathbf{I}$ in the corresponding solvents (see text for the detail). Note that in the inset, an additional data point for tetrahydrofuran has been added.

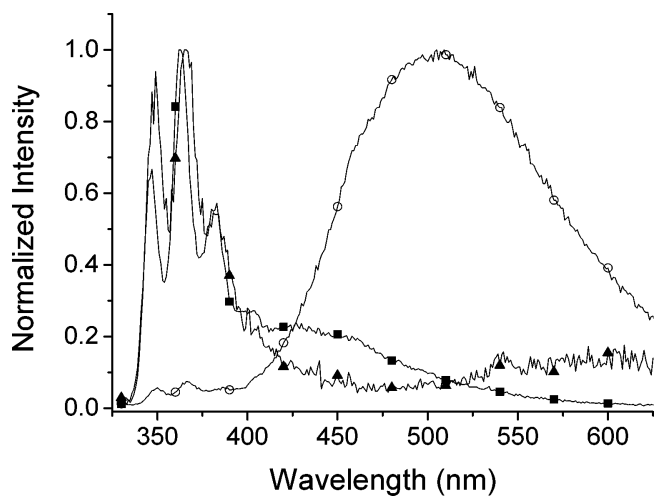

Figure 3. Emission spectra of II in diethyl ether (ם), dichloromethane $(\mathrm{O})$, and acetonitrile $(\boldsymbol{\nabla}) . \lambda_{\mathrm{ex}} \sim 330 \mathrm{~nm}$. Note that for clarity, the emission spectra have been normalized at $370 \mathrm{~nm}$.

$\mathrm{cm}^{-1}$ is calculated for $\mathbf{I}$. Accordingly, the change in dipole moment between ground and excited states is further deduced to be as large as $34.4 \mathrm{D}$ for I (see Supporting Information), ascertaining the electron-transfer origin of the emission band.

3.2. Photoinduced Electron Transfer in II. Upon elongating the bridge distance, one would expect to see the decrease of interaction/coupling between OMe-NP and CN-NP. We thus strategically designed and synthesized compounds II and III, in which the D/A distance has been stretched out by two and three norbornadienes, respectively. Theoretical approaches have estimated the center-to-center distances between the OMe-NP and CN-NP to be $6.4,10.8$, and $13.9 \AA$ for I, II, and III, respectively. Note that as we pointed out earlier, our goal is to differentiate the adiabatic versus nonadiabatic type of electrontransfer reaction, and consequently to quantify the corresponding interaction. Normally, one of the benchmarks for the nonadiabatic type of PET is a barrier induced by the weak coupling between locally excited (LE) and electron-transfer (ET) states. As a result, the rate of PET may be competitive with the relaxation rate of the LE state, resulting in a dual LE and ET emission. The latter emission is obscure in many PET molecules due to its transition forbidden character (vide infra). For II, a weak OMe-NP/CN-NP interaction is apparent because the absorption spectra (not shown here) are identical with the sum of the absorption spectra of individual OMe-NP and CN-NP. Further firm evidence is given by the corresponding emission spectra (Figure 3), in which dual emission was resolved among 
all the solvents studied. Details of the associated photophysical parameters are listed in Table 1. As a prototypical example, system II revealed dual emission with peak wavelengths at 360 $\mathrm{nm}\left(\mathrm{F}_{1}\right.$ band) and $430 \mathrm{~nm}\left(\mathrm{~F}_{2}\right.$ band) in, for example, diethyl ether. Although the $F_{1}$ band revealed solvent independence, the peak wavelength of the $F_{2}$ band is strongly affected by solvent polarity, being red shifted from $430 \mathrm{~nm}$ in diethyl ether to 600 $\mathrm{nm}$ in $\mathrm{CH}_{3} \mathrm{CN}$. Figure 4 reveals the relaxation dynamics of $\mathrm{F}_{1}$ and $F_{2}$ bands for $\mathbf{I I}$ in diethyl ether. The decay of the $F_{1}$ bands can be well fitted by two single-exponential components, these being $150 \pm 25$ ps and $10.7 \pm 0.2$ ns (see Table 1 ). Conversely, the $\mathrm{F}_{2}$ band consists of a rise component of $175 \pm 25 \mathrm{ps}$ and a decay of $10.5 \pm 0.2 \mathrm{~ns}$. The decay of $150 \pm 25 \mathrm{ps}$ monitored at the $\mathrm{F}_{1}$ band, within experimental error, is consistent with the rise $(175 \pm 25 \mathrm{ps})$ monitored at the $\mathrm{F}_{2}$ band, establishing a precursor-sater type of PET. Furthermore, the identical decay component of $\sim 10$ ns between the $F_{1}$ and $F_{2}$ bands leads us to conclude the establishment of equilibrium between the LE and ET states for II in diethyl ether. As a result, the PET can be described by a weak coupling between the LE and ET state (Scheme 2), with the associated time-dependent concentration of locally excited [L*] and electron-transfer [ $\left.\mathrm{E}^{*}\right]$ states expressed as $^{12}$

$$
\begin{aligned}
& \stackrel{\mathrm{LE}}{\mathrm{k}_{\mathrm{L}^{*}}} \downarrow \frac{\mathrm{k}_{\mathrm{et}}}{\mathrm{k}_{\text {-et }}} \mathrm{ET} \\
& {\left[\mathrm{L}^{*}\right]=\left[\mathrm{L}^{*}\right]_{0}\left(\alpha_{1}^{\mathrm{L}^{*}} \mathrm{e}^{-t / \tau_{1}}+\alpha_{2}^{\mathrm{L}^{*}} \mathrm{e}^{-t / \tau_{2}}\right) \quad\left[\mathrm{E}^{*}\right]=\left[\mathrm{L}^{*}\right]_{0}\left(\alpha_{1}^{\mathrm{E}^{*}} \mathrm{e}^{-t / \tau_{1}}+\alpha_{2}^{\mathrm{E}^{*}} \mathrm{e}^{-t / \tau_{2}}\right)} \\
& \alpha_{1}^{\mathrm{L}^{*}}=\frac{\gamma_{\mathrm{L}^{*}}-\gamma_{2}}{\gamma_{1}-\gamma_{2}} \quad \alpha_{2}^{\mathrm{L}^{*}}=\frac{\gamma_{1}-\gamma_{\mathrm{L}^{*}}}{\gamma_{1}-\gamma_{2}} \quad-\alpha_{1}^{\mathrm{E}^{*}}=\alpha_{2}^{\mathrm{E}^{*}} \\
& \gamma_{1}, \gamma_{2}=\tau_{1}^{-1}, \tau_{2}^{-1}= \\
& 1 / 2\left\{\left(\gamma_{\mathrm{L}^{*}}+\gamma_{\mathrm{E}^{*}}\right) \pm\left[\left(\gamma_{\mathrm{L}^{*}}-\gamma_{\mathrm{E}^{*}}\right)^{2}+4 k_{-\mathrm{et}} k_{+\mathrm{et}}\right]^{1 / 2}\right\} \\
& \gamma_{\mathrm{L}^{*}}=\gamma_{2}+\alpha_{1}^{\mathrm{L}^{*}}\left(\gamma_{1}-\gamma_{2}\right)=k_{\mathrm{L}^{*}}+k_{+\mathrm{et}} \\
& \gamma_{\mathrm{E}^{*}}=\gamma_{1}-\alpha_{1}^{\mathrm{L}^{*}}\left(\gamma_{1}-\gamma_{2}\right)=k_{\mathrm{E}^{*}}+k_{-\mathrm{et}}
\end{aligned}
$$

According to the much longer population decay time of $\sim 10$ ns for II in diethyl ether, it is reasonable to assume $k_{+ \text {et }}, k_{- \text {et }} \gg$ $k_{\mathrm{L}^{*}}, k_{\mathrm{E}^{*}}$, such that the equilibrium constant $K_{\text {eq }}$ can be expressed as

$$
K_{\mathrm{eq}}=\frac{k_{+\mathrm{et}}}{k_{-\mathrm{et}}} \cong \frac{\left[\mathrm{E}^{*}\right]}{\left[\mathrm{L}^{*}\right]}(t \rightarrow \infty)=\frac{\alpha_{1}^{\mathrm{L}^{*}}}{\alpha_{2}^{\mathrm{L}^{*}}}
$$

Upon a best fit of the he $F_{1}$ component (see Table 1), $\alpha_{1}^{L^{*}}$ and $\alpha_{2}^{L^{*}}$ were deduced to be 0.54 and 0.46 , respectively, giving a $K_{\text {eq }}$ value of 1.18 in diethyl ether at $298 \mathrm{~K}$. This corresponds to a $\Delta G$ of $-0.1 \mathrm{kcal} / \mathrm{mol}$. Under the existence of a fast equilibrium, the rate of population decay for both $F_{1}$ and $F_{2}$ bands can be expressed as $1 / \tau_{1}=1 / \tau_{2} \approx k_{+\mathrm{et}}+k_{-\mathrm{et}}=6.6 \times$ $10^{9} \mathrm{~s}^{-1}$. This, in combination with eq 3 , renders $3.6 \times 10^{9} \mathrm{~s}^{-1}$ and $3.0 \times 10^{9} \mathrm{~s}^{-1}$ for the forward $\left(k_{+\mathrm{et}}\right)$ and backward $\left(k_{-\mathrm{et}}\right)$

\begin{tabular}{|c|c|c|c|c|c|c|}
\hline \multicolumn{2}{|l|}{$\mathrm{I}$} & \multicolumn{3}{|c|}{$\lambda_{\text {em,max }} / n m$} & $\tau / \mathrm{ns}$ & $\Phi_{\mathrm{f}}$ \\
\hline \multicolumn{2}{|c|}{ cyclohexane } & \multicolumn{3}{|c|}{380} & 5.3 & 0.68 \\
\hline \multicolumn{2}{|c|}{ diethyl ether } & \multicolumn{3}{|c|}{410} & 5.7 & 0.48 \\
\hline \multicolumn{2}{|c|}{ Ethyl acetate } & \multicolumn{3}{|c|}{440} & 5.4 & 0.37 \\
\hline \multicolumn{2}{|c|}{ tetrahydrofuran } & \multicolumn{3}{|c|}{440} & 5.9 & 0.40 \\
\hline \multirow{2}{*}{\multicolumn{2}{|c|}{$\begin{array}{l}\text { dichloromethane } \\
\text { acetonitrile }\end{array}$}} & \multicolumn{3}{|c|}{450} & 5.2 & 0.34 \\
\hline & & \multicolumn{3}{|c|}{510} & 6.3 & 0.24 \\
\hline II & $\lambda_{\mathrm{em}} / \mathrm{nm}$ & temp/K & \multicolumn{2}{|c|}{$\tau_{1} / \mathrm{ps}$} & $\tau_{2} / \mathrm{ns}$ & $\Phi_{\mathrm{ET}}$ \\
\hline \multirow[t]{7}{*}{ diethyl ether } & \multirow[t]{6}{*}{360} & 298 & \multicolumn{2}{|c|}{$150(0.54)$} & \multicolumn{2}{|c|}{$10.7(0.46) \quad 0.12$} \\
\hline & & 243 & \multicolumn{2}{|c|}{$330(0.15)$} & $9.6(0.85)$ & \\
\hline & & 233 & \multicolumn{2}{|c|}{$526(0.14)$} & $8.0(0.86)$ & \\
\hline & & 223 & \multicolumn{2}{|c|}{$640(0.16)$} & $9.2(0.84)$ & \\
\hline & & \multirow{2}{*}{$\begin{array}{l}213 \\
203\end{array}$} & $885(0$. & & $8.3(0.84)$ & \\
\hline & & & 9980. & & $10.7(0.82)$ & \\
\hline & 430 & RT & $175(-$ & $0.36)$ & $10.5(0.64)$ & \\
\hline dichloro- & 366 & RT & $43(0$. & & $8.7(0.01)$ & 0.18 \\
\hline & 505 & RT & 40.5 & $-0.12)$ & $9.0(0.88)$ & \\
\hline acetonitrile & 367 & RT & $34(0$. & & $3.4(0.08)$ & $2.5 \times 10^{-3}$ \\
\hline & 600 & RT & -35 & & 3.1 & \\
\hline III & & $\mathrm{em} / \mathrm{nm}$ & temp/K & & ns & $\tau_{2} / \mathrm{ns}$ \\
\hline $\begin{array}{l}\text { diethyl ether } \\
\text { nat }\end{array}$ & & 330 & RT & 0.03 & & \\
\hline & & 365 & RT & 11.3 & & \\
\hline dicnioromett & Ial & 366 & 298 & 1.0 & & \\
\hline & & & 283 & 1.3 & & \\
\hline & & & 263 & 1.4 & & \\
\hline & & & 243 & 1.6 & & \\
\hline & & & 223 & 1.9 & & \\
\hline & & & 203 & 2.4 & & \\
\hline & & 535 & RT & 0.9 ( & $-0.35)$ & $.2(0.65)$ \\
\hline acetonitrile & & 330 & RT & 0.04 & & \\
\hline & & 366 & RT & 0.5 & & \\
\hline
\end{tabular}
rates of PET at $298 \mathrm{~K}$. Increasing solvent polarity leads to a decrease of the $F_{1}$ intensity, indicating a faster PET process. This viewpoint was supported by nearly system-response-limited
TABLE 1: Emission Lifetimes and Pre-exponential Factors (in Parentheses) of I-III in Various Solvents at $298 \mathrm{~K}$ and the Temperature-Dependent Relaxation Dynamics in Diethyl Ether (II) and Dichloromethane (III) $\left(\lambda_{\mathrm{ex}} \sim 320 \mathrm{~nm}\right)^{a}$

${ }^{a}$ Note that the experimental error for the fitted time constant and quantum yield is less than $\sim 20 \%$.

( $\sim 30 \mathrm{ps}$ ) relaxation dynamics of $\mathrm{F}_{1}$ (decay) and $\mathrm{F}_{2}$ (rise) components in either $\mathrm{CH}_{2} \mathrm{Cl}_{2}$ or $\mathrm{CH}_{3} \mathrm{CN}$. Moreover, the reaction predominantly favors the product (i.e., the ET state) in both $\mathrm{CH}_{2} \mathrm{Cl}_{2}$ and $\mathrm{CH}_{3} \mathrm{CN}$, as indicated by the ratio $\alpha_{1}^{\mathrm{L}^{*}} / \alpha_{2}^{\mathrm{L}^{*}}>99$ in both solvents.

One remarkable difference between the studied systems (II and III) and most PET molecules so far is that the lowest lying $\mathrm{S}_{0}-\mathrm{S}_{1}$ energy gap for the electron acceptor, i.e., CN-NP, is lower than that of the donor (OMe-NP). Because the emission of OMeNP strongly overlaps with the absorption spectrum of CN-NP (see Figure 5), upon the excitation of OMe-NP, energy transfer should take place from OMe-NP to $\mathrm{CN}-\mathrm{NP}$. If the energytransfer process is faster than the PET process, PET is essentially from OMe-NP (HOMO) to the half-filled orbital of CN-NP (HOMO) depicted in Scheme 3. Indeed, the steady-state emission spectroscopy has confirmed this to be the case by resolving solely the CN-NP LE band $(370 \mathrm{~nm})$ and the chargetransfer emission, with the lack of OMe-NP emission $(330 \mathrm{~nm})$. The rate of Förster type resonance energy transfer, $k_{\mathrm{F}}(r)$, can be expressed as

$$
\begin{aligned}
& k_{\mathrm{F}}(r)=\frac{9000(\ln 10) \kappa^{2} Q_{\mathrm{D}}}{128 \tau_{\mathrm{D}} r^{6} N_{\mathrm{A}} \pi^{5} n_{\mathrm{d}}^{4}} I(\lambda) \\
& \qquad I(\lambda)=\int_{0}^{\infty} F_{\mathrm{D}}(\lambda) \epsilon_{\mathrm{A}}(\lambda) \lambda^{4} \mathrm{~d} \lambda
\end{aligned}
$$

where $Q_{\mathrm{D}}$ is the quantum yield of donor (OMe-NP) in the absence of acceptor (CN-NP), $n_{\mathrm{d}}$ is the refractive index, which 


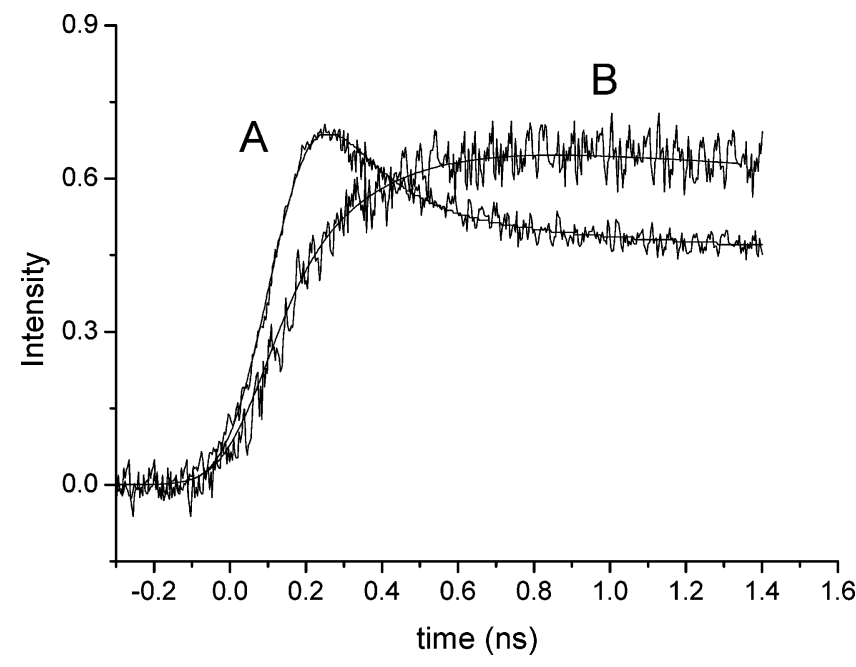

Figure 4. Relaxation dynamics of II in diethyl ether monitored at $298 \mathrm{~K}$ at (A) $350 \mathrm{~nm}$ and (B) $550 \mathrm{~nm}$. $\lambda_{\mathrm{ex}} \sim 270 \mathrm{~nm}$. Note that with best curve fitting, the fast decay of the $350 \mathrm{~nm}(150 \mathrm{ps})$ emission correlates very well with the rise of the $550 \mathrm{~nm}$ emission (207 ps). Both have population decay times of $10 \mathrm{~ns}$.

SCHEME 2: Proposed Adiabatic (A, Compound I) and Nonadiabatic (B, Compounds II and III) Types of Electron-Transfer Reactions ${ }^{a}$

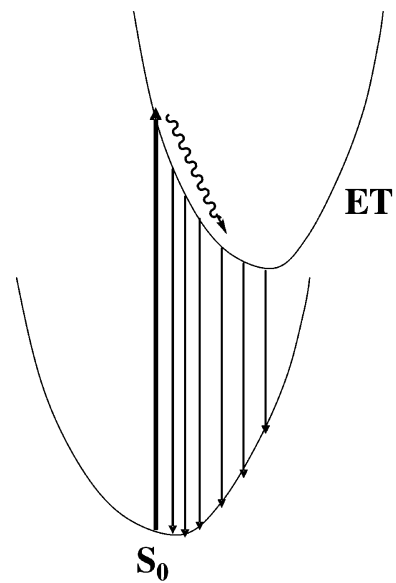

A

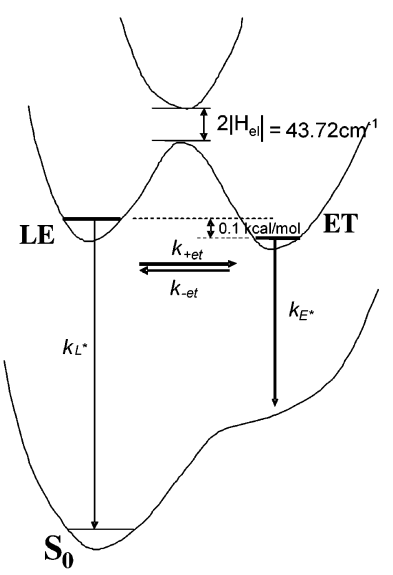

B
${ }^{a}$ Note that numbers presented in B are data obtained from II in diethyl ether.

is 1.35 and 1.42 in diethyl ether and $\mathrm{CH}_{2} \mathrm{Cl}_{2}$, respectively, $\tau_{\mathrm{D}}$ is the lifetime of the donor in the absence of an acceptor, $F_{\mathrm{D}}(\lambda)$ is the corrected fluorescence intensity of the donor in the wavelength range $\lambda+\Delta \lambda$, with the total intensity normalized to unity, $\epsilon_{\mathrm{A}}(\lambda)$ is the extinction coefficient of the acceptor at $\lambda$, and $\kappa$ is a factor describing the relative orientation in space of the transition dipoles of the donor and acceptor. The spectral overlap between OMe-NP (fluorescence) and CN-NP (absorption), is depicted in the inset of Figure 5. For system II, we took $\kappa$ to be $\sim 1$ (cosine of the angle $\left(\sim 0^{\circ}\right)$ of the transition dipole between $\mathrm{D}$ and $\mathrm{A}$ moieties). $Q_{\mathrm{D}} / \tau_{\mathrm{D}}$ is essentially equivalent to the radiative lifetime of the donor, which was calculated to be $9.8 \times 10^{7} \mathrm{~s}^{-1}$. In this case, $r$ is fixed to be the center-to-center distance between D and A moieties, which is theoretically calculated to be $10.8 \AA$ for system II. As a result, the rate of energy transfer was calculated to be $3.3 \times 10^{11} \mathrm{~s}^{-1}$, which is much faster than the experimentally observed decay rate of the $F_{1}$ band. We thus conclude that upon excitation of OMe-NP, energy transfer takes place (to $\mathrm{CN}-\mathrm{NP}$ ) in a much faster manner, followed by the electron transfer from OMe-NP

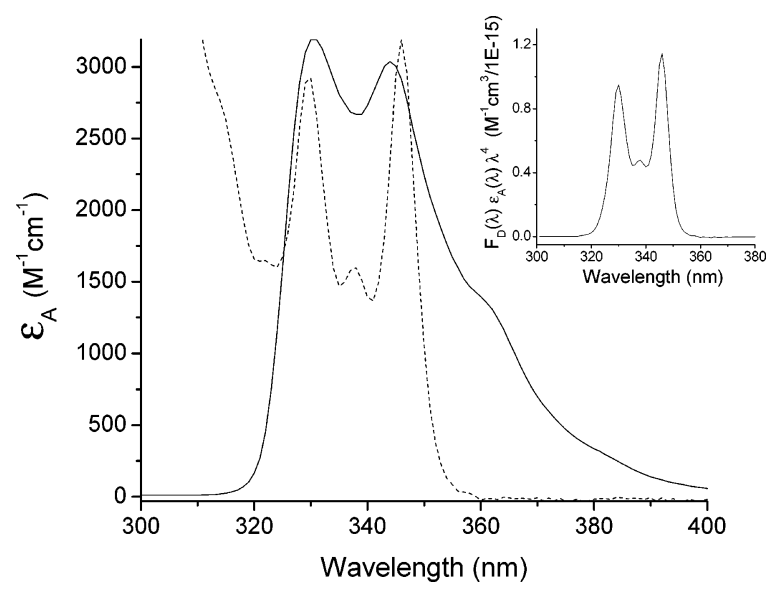

Figure 5. Absorption (in terms of molar extinction coefficient) of CNNP (dashed line) and emission spectrum of OMe-NP (solid line) in dichloromethane. Note that the intensity scale of the emission spectrum of OMe-NP is arbitrary and has been normalized at $350 \mathrm{~nm}$ with respect to the absorption spectrum. Inset: $F_{\mathrm{D}}(\lambda) \epsilon_{\mathrm{A}}(\lambda) \lambda^{4}\left(\mathrm{M}^{-1} \mathrm{~cm}^{3}\right)$ versus $\lambda$ $(\mathrm{nm})$. The intensity of $F_{\mathrm{D}}(\lambda)$ has been normalized.

\section{SCHEME 3}

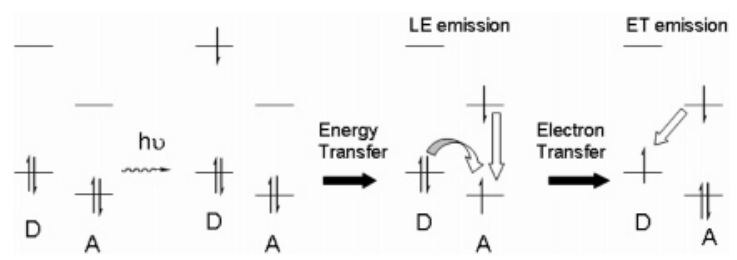

to $\mathrm{CN}-\mathrm{NP}$, as depicted in Scheme 3. Note that because the time scale of the energy transfer is much shorter than that of the PET reaction, the above kinetic derivations (e.g., eqs 2 and 3) still hold valid for II. Vice versa, only PET takes place upon direct excitation (e.g., > $340 \mathrm{~nm}$ ) of CN-NP, for which the PET mechanism is essentially the same as that of OMe-NP excitation. However, it is worthy to note that, limited by the excitation source $(260-270 \mathrm{~nm}$, third harmonic of the Ti:Sapphire laser) in this study, relaxation dynamics based on simultaneous excitation of both D and A moieties is unavoidable.

We then made an attempt to calculate the thermodynamics of the PET reaction forII. For a weakly interacted PET process, the associated free energy of reaction can be estimated by the Marcus-Weller equation, expressed as

$$
\begin{aligned}
\Delta G=E_{\mathrm{ox}}(\mathrm{D})- & E_{\mathrm{red}}(\mathrm{A})-E_{00}-\left(e^{2} / 4 \pi \epsilon_{\mathrm{s}} \epsilon_{0} r_{\mathrm{c}}\right)- \\
& \left(e^{2} / 8 \pi \epsilon_{0}\right)\left(1 / r_{\mathrm{D}^{+}}+1 / r_{\mathrm{A}^{-}}\right)\left(1 / 9.0-1 / \epsilon_{\mathrm{s}}\right)
\end{aligned}
$$

where $E_{\mathrm{ox}}(\mathrm{D})$ and $E_{\mathrm{red}}(\mathrm{A})$ are the oxidation and reduction potentials of OMe-NP and $\mathrm{CN}-\mathrm{NP}$ molecules, respectively, measured in dichloromethane (in this study). $E_{00}$ is the energy of the $0-0$ transition of the chromophore where PET takes place. On the basis of the above argument, $E_{00}$ in eq 5 should correspond to the $0-0$ transition for $\mathrm{CN}-\mathrm{NP}$, which is calculated to be $3.57 \mathrm{eV}, r_{\mathrm{D}^{+}}$and $r_{\mathrm{A}^{-}}$are effective ionic radii, 9.0 and $\epsilon_{\mathrm{S}}$ denote the dielectric constant of $\mathrm{CH}_{2} \mathrm{Cl}_{2}$ and solvent applied, respectively, and $r_{\mathrm{c}}$ is the center-to-center distance between dimethoxynaphthalene and dicyanonaphthalene, which was estimated to be $10.8 \AA$ on the basis of a geometry optimized structure (see Experimental Section). Values of $E_{\mathrm{ox}}(\mathrm{D}), E_{\mathrm{red}}(\mathrm{A})$ and $E_{00}(\mathrm{CN}-\mathrm{NP})$ were obtained to be $+1.4 \mathrm{eV},-2.05$ and +3.57 $\mathrm{eV}(347 \mathrm{~nm})$ in $\mathrm{CH}_{2} \mathrm{Cl}_{2}$, respectively. An approximation was further made on $r=r_{\mathrm{D}^{+}}=r_{\mathrm{A}^{-}}=4.5 \AA$ on the basis of the geometry optimized dicyanonaphthalene (or dimethoxynaph- 


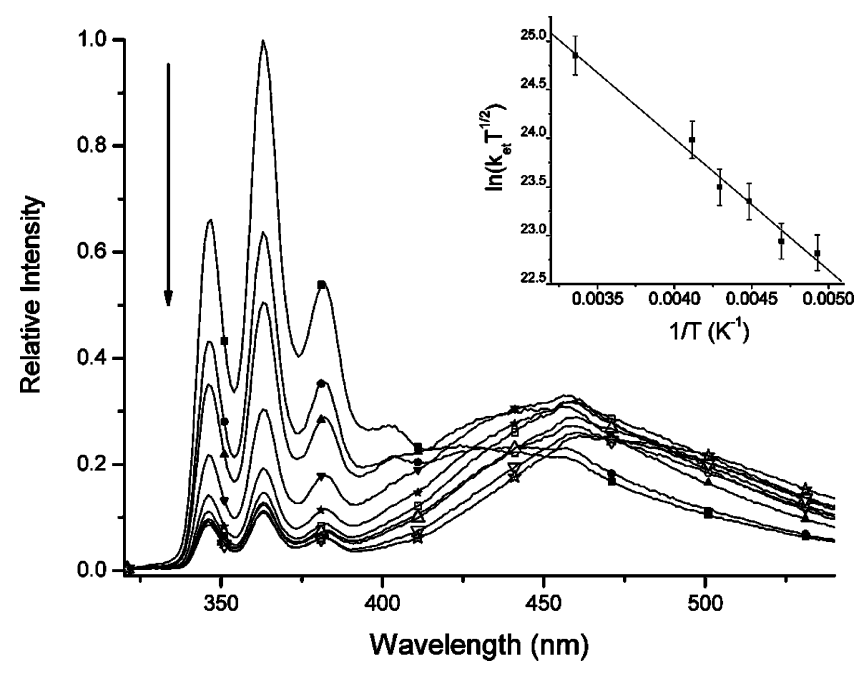

Figure 6. Temperature-dependent emission spectra of II in diethyl ether at $293 \mathrm{~K}(\boldsymbol{\square}), 283 \mathrm{~K}(\bullet), 273 \mathrm{~K}(\boldsymbol{\Delta}), 263 \mathrm{~K}(\boldsymbol{\nabla}), 253 \mathrm{~K}(\star), 243$ $\mathrm{K}(\square) 233 \mathrm{~K}(\square) 223 \mathrm{~K}(\triangle) 213 \mathrm{~K}(\nabla) . \lambda_{\mathrm{ex}}: 330 \mathrm{~nm}$. Inset: $\ln \left(k_{\mathrm{et}} T^{1 / 2}\right)$ versus $1 / T$ for $\mathbf{I I}$ in diethyl ether. A corresponding best linear fit gives $\Delta G^{+}$and intercept to be $2.7 \pm 0.3 \mathrm{kcal} / \mathrm{mol}$ and 29.4 , respectively.

thalene). With all of the values substituted into eq 5 , the free energies for PET were calculated to be exergonic in diethyl ether $(-0.9 \mathrm{kcal} / \mathrm{mol}), \mathrm{CH}_{2} \mathrm{Cl}_{2}(-6.2 \mathrm{kcal} / \mathrm{mol})$, and $\mathrm{CH}_{3} \mathrm{CN}(-9.8$ $\mathrm{kcal} / \mathrm{mol})$. It is important to note that a $\Delta G$ value of $-0.9 \mathrm{kcal} /$ mol deduced from eq 5 is consistent with the establishment of equilibrium $(\Delta G \sim-0.1 \mathrm{kcal} / \mathrm{mol})$ resolved from the relaxation dynamics.

To gain further insight into the PET dynamics, we then performed temperature-dependent studies of II in diethyl ether (see Table 1). The use of diethyl ether is simply due to the fact that the associated rate of PET for II is slowest among the three solvents applied and hence can be fitted precisely via our picosecond time-resolved system. At the high-temperature regime, a temperature-dependent electron-transfer rate $k_{\text {et }}$, according to the Marcus theory of electron transfer, ${ }^{13}$ can be expressed as

$$
\ln \left(k_{\mathrm{et}} T^{1 / 2}\right)=\ln \left[\frac{2 \pi}{\left(4 \pi \lambda k_{\mathrm{B}}\right)^{1 / 2} \hbar}\left|H_{\mathrm{el}}\right|^{2}\right]-\frac{\Delta G^{\dagger}}{k_{\mathrm{B}} T}
$$

where $\left|H_{\mathrm{el}}\right|$ involves an electron-coupling matrix element between LE and ET states, $\lambda$ denotes the reaction reorganization energy incorporating both nuclear (i.e., Franck Condon factor) and solvent reorganization energy. $\Delta G^{+}$and $\Delta G$ symbolize the reaction activation energy and free energy, respectively, with the relationship $\Delta \mathrm{G}^{+}=(\Delta G+\lambda)^{2} / 4 \lambda .{ }^{13}$ One would thus expect $\ln \left(k_{\mathrm{et}} T^{1 / 2}\right)$ to be linearly dependent on $1 / T$.

In this approach, the temperature gradient was only varied from 300 to $200 \mathrm{~K}$, so that a large change of solvent viscosity could be prevented. ${ }^{14}$ Figure 6 depicts the temperature-dependent steady-state emission of II in diethyl ether. Obviously, the intensity ratio for $F_{1} / F_{2}$ as a function of temperature was irregular, which decreased as the temperature was decreased from 300 to $250 \mathrm{~K}$, whereas it only underwent slight changes at $250-200 \mathrm{~K}$. The results indicated competitive pathways between dynamics and thermodynamics under an equilibrium condition. Such steady-state complexity becomes straightforward in the relaxation dynamics shown in Table 1, in which the observed fast decay component of the $\mathrm{F}_{1}$ band decreases upon decreasing the temperature, accompanied by the increase of the rise time of the $F_{2}$ band. As shown in Table 1, the correlation between decay $\left(\mathrm{F}_{1}\right)$ and rise $\left(\mathrm{F}_{2}\right)$, within experimental error, is very good. Nevertheless, the long population decay time exists in any monitored emission, indicating the existence of equilibrium throughout the temperature range of 300-200 K.

As for the kinetic approaches, either the decay dynamics of the acceptor (i.e., the $\mathrm{F}_{1}$ band) or the rise dynamics of the ET band (the $\mathrm{F}_{2}$ band) can be monitored to extract $k_{+\mathrm{et}}$ (or $k_{-\mathrm{et}}$ ) For the case of II in diethyl ether involving equilibrium, the observed decay rate $k_{\mathrm{obs}}$ of the $\mathrm{F}_{1}$ band for II can be expressed as (7) by solving eq 2 with the elimination of the square term

$$
k_{\mathrm{obs}}=k_{+\mathrm{et}}+k_{-\mathrm{et}}+\frac{k_{\mathrm{L}^{*}}+k_{\mathrm{E}^{*}}}{2}+\frac{\left(k_{+\mathrm{et}}-k_{-\mathrm{et}}\right)\left(k_{\mathrm{L}^{*}}-k_{\mathrm{E}^{*}}\right)}{2\left(k_{+\mathrm{et}}+k_{-\mathrm{et}}\right)}
$$

of $\left(k_{\mathrm{L}} *-k_{\mathrm{E}} *\right)$. Evaluation of $k_{\mathrm{obs}}$ can be simplified to $k_{\mathrm{obs}}=$ $k_{+ \text {et }}+k_{- \text {et }}$ by making the approximation that $k_{\mathrm{L}^{*}}$ and $k_{\mathrm{E}^{*}}$ are small compared to $k_{- \text {et }}$ and $k_{+ \text {et }}$ in the range of temperatures studied. This assumption should be valid due to the few tens to hundreds of picoseconds of the PET time scale, which is much faster than the approximately few nanoseconds of the decay time for both the LE and ET states. As a result, $k_{+\mathrm{et}}$ can be extracted from $k_{\mathrm{obs}}=k_{+\mathrm{et}}+k_{-\mathrm{et}}$ and the equilibrium constant obtained from

$$
K_{\mathrm{eq}}=\frac{k_{+\mathrm{et}}}{k_{-\mathrm{et}}}=\frac{\alpha_{1}^{\mathrm{L}^{*}}}{\alpha_{2}^{\mathrm{L}^{*}}}
$$

The inset of Figure 6 depicts a straight-line plot for $\ln \left(k_{\mathrm{et}} T^{1 / 2}\right)$ versus $1 / T$ in diethyl ether for II. The slope and intercept give the PET barrier $\left(\Delta G^{+}\right) 2.7 \pm 0.3 \mathrm{kcal} / \mathrm{mol}$. Because $\Delta G$ has been experimentally resolved to be $-0.1 \mathrm{kcal} / \mathrm{mol}$ (vide supra), $\lambda$ can thus be extracted by solving $\Delta G^{+}=(\Delta G+\lambda)^{2} / 4 \lambda$ with known $\Delta G^{+}$and $\Delta G$. The resulting $\lambda$ value $(12.5 \mathrm{kcal} / \mathrm{mol})$ for II in diethyl ether is then plugged into the intercept term in eq 6 to deduce a $\left|H_{\mathrm{el}}\right|$ value of $21.9 \mathrm{~cm}^{-1}$, which is apparently much smaller than the thermal energy at $298 \mathrm{~K}\left(\sim 200 \mathrm{~cm}^{-1}\right)$, firmly supporting the operation of a nonadiabatic type of PET process in system II.

3.3. Photoinduced Electron Transfer in III. On the basis of the same methodology, we then focus on the spectroscopy and relaxation dynamics of III. Because the elongation of norbornadiene bridges causes a smaller D/A coupling constant, both rates of energy transfer and PET in III are expected to be slower than that of II. The viewpoint of the relatively slow PET rate in III can be supported from the steady-state approach, in which the $F_{2}$ band is obscure for III in diethyl ether (see Figure 7). Dynamically, we only resolved an exceedingly long lifetime ( $\sim 11.3 \mathrm{~ns}$ ) for the $\mathrm{F}_{1}$ band in diethyl ether. On the other hand, PET in III is apparently operative in $\mathrm{CH}_{2} \mathrm{Cl}_{2}$, as supported by the observation of dual emission and equivalent decay (1.0 ns) and rise ( $0.9 \mathrm{~ns}$, see Table 1 and inset of Figure 7) components for $F_{1}$ and $F_{2}$ bands, respectively. Note that, as shown in Figure 7 and Table 1, although the rate of PET for III in $\mathrm{CH}_{3} \mathrm{CN}$ is faster than that in, for example, $\mathrm{CH}_{2} \mathrm{Cl}_{2}$, the associated ET emission is not resolvable. The dominant quenching of the excited-state ET species by increasing the polar environment is not uncommon, especially in strong polar solvents such as $\mathrm{CH}_{3} \mathrm{CN}$, alcohols, and water, where the ultrafast radiationless transition is generally observed for the ET emission. ${ }^{15}$ Dramatic polarity effects for the nonradiative ET state (electron separated form) $\rightarrow \mathrm{S}_{0}$ (neutral form) back electron transfer have been reported in several systems. ${ }^{16}$ In addition, as the local excitation (LE)-ET zero-order gap increases by increasing the solvent polarity, the radiative decay rate of the ET band decreases 


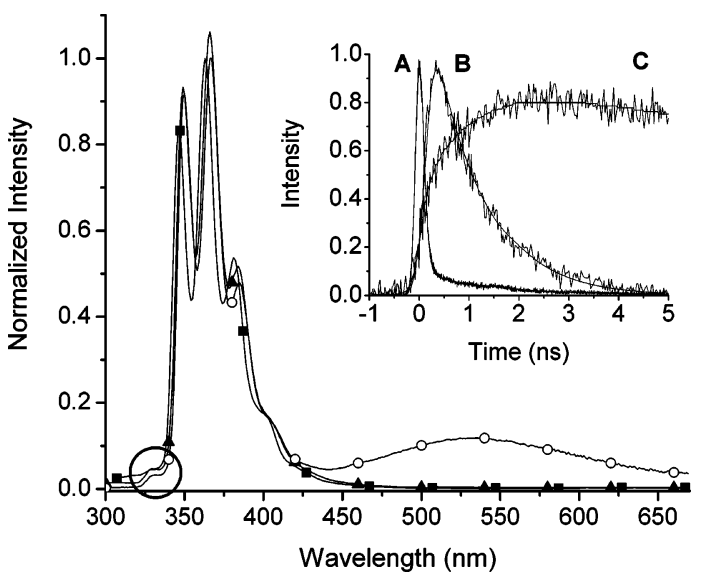

Figure 7. Fluorescence spectra of III in diethyl ether (ם), acetonitrile $(\boldsymbol{\Lambda})$, and dichloromethane (O). Inset: relaxation dynamics of III in dichloromethane monitored at (A) $330 \mathrm{~nm}$, (B) $370 \mathrm{~nm}$, and (C) 535 $\mathrm{nm}$ at $298 \mathrm{~K}$. $\lambda_{\mathrm{ex}} \sim 270 \mathrm{~nm}$.

accordingly due to the reduction in LE/ET interaction, and hence a larger fraction of the forbidden transition. The strong solvent dependence suggests that most of the radiative rate for the ET species in moderately polar solvents seems to be due to LEET-state mixing. ${ }^{17}$ The small radiative decay rate in combination with the fast rate of the radiationless transition rationalizes the lack of observing ET emission for III in $\mathrm{CH}_{3} \mathrm{CN}$ via the steadystate approach.

In view of the energy transfer, as shown in Figure 7, one can promptly perceive a very small but nonnegligible portion of emission ( $320-340 \mathrm{~nm}$; see gray circled area in Figure 7) attributed to the OMe-NP emission, which is apparently missing in system II (see Figures 3 and 7 for comparison). We thus were able to monitor the relaxation dynamics at the OMe-NP band (e.g., $330 \mathrm{~nm}$ ) and resolve a near response limited decay time of $30-40 \mathrm{ps}$ in all solvents studied (see Table 1 and inset of Figure 7). Theoretically, one can use the Förster type of resonance energy transfer (eq 4) to estimate the energy-transfer rate by plugging $\kappa$ and $r$ to be $-1 / 2$ (the cosine of the angle $\left(\sim 120^{\circ}\right)$ of the transition dipole between D and A moieties) and $13.9 \AA$, respectively, for III. As a result, the energy-transfer rate was estimated to be $\sim 30 \mathrm{ps}^{-1}$, which is consistent with that obtained from the time-resolved measurement.

We then focused on the temperature-dependent PET reaction in $\mathrm{CH}_{2} \mathrm{Cl}_{2}$, in which III revealed dual emission (see Table 1 and Figure 7), and the decay of the $F_{1}$ band correlated very well with the rise of the $\mathrm{F}_{2}$ band at $298 \mathrm{~K}$ (see inset of Figure 7). Figure 8 shows the results of steady-state temperaturedependent emission in $\mathrm{CH}_{2} \mathrm{Cl}_{2}$, in which the intensity of the $\mathrm{F}_{1}$ band increases as the temperature decreases from 283 to 203 $\mathrm{K}$, indicating the retardation of PET at lower temperatures, and that the PET for III in $\mathrm{CH}_{2} \mathrm{Cl}_{2}$ is a highly exergonic process. Due to the irreversible as well as much slower PET process for III in $\mathrm{CH}_{2} \mathrm{Cl}_{2}$, eq 7 can be simplified to

$$
k_{\mathrm{obs}}=k_{\mathrm{L}^{*}}+k_{+\mathrm{et}}(T)=k_{\mathrm{r}}+k_{\mathrm{nr}}(T)+k_{+\mathrm{et}}(T)
$$

where $k_{\mathrm{r}}$ is the radiative decay rate of the $\mathrm{F}_{1}$ band and $k_{\mathrm{nr}}$ denotes the sum of all nonradiative decay rates of III except for $k_{\text {et }}$. Due to the slow $k_{+\mathrm{et}}(T), k_{\mathrm{r}}+k_{\mathrm{nr}}(T)$ in eq 8 becomes comparable and thus cannot be neglected. Throughout the temperaturedependent studies, it is appropriate to use the observed decay rate of CN-NP only in each temperature to represent $k_{\mathrm{r}}+k_{\mathrm{nr}^{-}}$ $(T)$, so that the temperature-dependent $k_{+ \text {et }}$ can be extracted directly from $k_{\mathrm{obs}}-k_{\mathrm{r}}-k_{\mathrm{nr}}(T)$. As shown in the inset of Figure

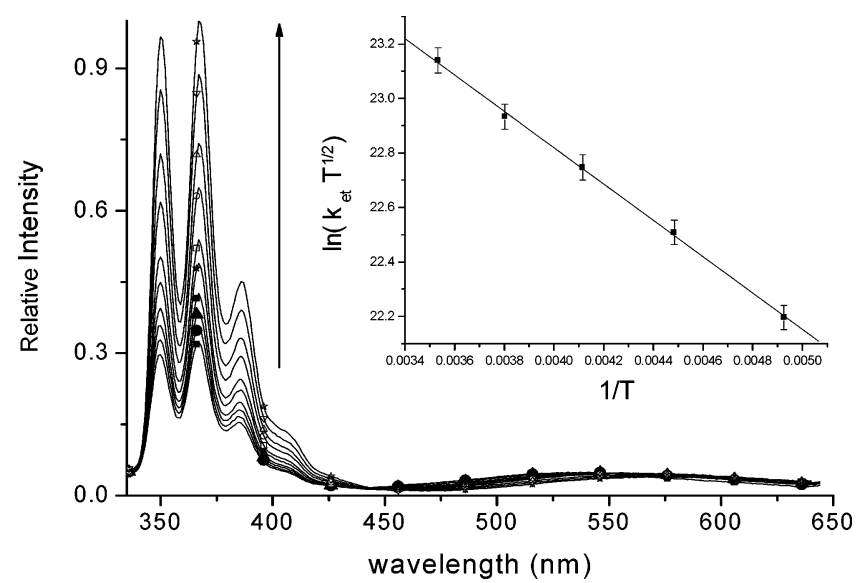

Figure 8. Temperature-dependent emission spectra of III in dichloromethane at $298 \mathrm{~K}(\boldsymbol{\square}), 283 \mathrm{~K}(\bullet), 273 \mathrm{~K}(\boldsymbol{\Delta}), 263 \mathrm{~K}(\boldsymbol{\nabla}), 253 \mathrm{~K}$

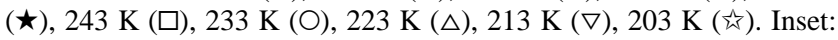
$\ln \left(k_{\mathrm{et}} T^{1 / 2}\right)$ versus $1 / T$ for III in $\mathrm{CH}_{2} \mathrm{Cl}_{2}$. A corresponding best linear fit gives $\Delta G^{+}$and intercept to be $1.3 \pm 0.6 \mathrm{kcal} / \mathrm{mol}$ and 25.5 , respectively. Note that data points were collected every other $20 \mathrm{~K}$ in the range $283-203 \mathrm{~K}$.

8 , the plot of $\ln \left(k_{+\mathrm{et}} T^{1 / 2}\right)$ versus $1 / T$ reveals a sufficiently straight line. Accordingly, the $\Delta G^{+}$and intercept were deduced to be $1.3 \pm 0.6 \mathrm{kcal} / \mathrm{mol}$ and 25.5 , respectively. Because the equilibrium is strongly in favor of the ET state in $\mathrm{CH}_{2} \mathrm{Cl}_{2}$, it is not feasible to extract the $\Delta G$ value experimentally. Alternatively, $\Delta G$ was estimated to be $-5.4 \mathrm{kcal} / \mathrm{mol}$ from eq 5 , giving a known $E_{00}(347 \mathrm{~nm}, 3.57 \mathrm{eV}), E_{\mathrm{ox}}(1.4 \mathrm{eV}), E_{\text {red }}(-2.05 \mathrm{eV})$, and $r_{\mathrm{c}}(13.9 \AA)$. Accordingly, $\lambda$ was then deduced to be 13.9 $\mathrm{kcal} / \mathrm{mol}$. With a known intercept value of 25.5 and $\lambda=13.9$ $\mathrm{kcal} / \mathrm{mol},\left|H_{\mathrm{el}}\right|$ was then calculated to be $3.2 \mathrm{~cm}^{-1}$.

3.4. Theoretical Approach. Bearing the $\left|H_{\mathrm{el}}\right|$ value obtained for II $\left(21.9 \mathrm{~cm}^{-1}\right)$ and III $\left(3.2 \mathrm{~cm}^{-1}\right)$ in mind, we then returned to system I with the aim of probing the $\left|H_{\mathrm{el}}\right|$. Qualitatively, the strong D/A interaction in $\mathbf{I}$ can be viewed from the frontier orbital analyses. Figure 9A reveals the TD-DFT/6-31G* approach on the HOMO and LUMO of system I, mainly involved in the lowest lying transition in the singlet manifold. As expected, the HOMO and LUMO are ascribed to dimethoxynaphthalene and dicyanonaphthalene moieties, respectively. Note that the rate of electron transfer should be governed by the overlap of frontier orbitals between dimethoxynaphthalene (HOMO) and dicyanonaphthalene (LUMO). Evidently, a close examination indicates that for both frontier orbitals, great extension of the electron density was populated at the norbornadiene bridge, resulting in a significant overlap between dicyanonaphthalene and dimethoxynaphthalene and hence a large coupling constant. Quantitatively, on the basis of the generalized Mulliken-Hush (GMH) theory, ${ }^{18}$ Cave and Newton $^{19}$ have developed the GMH formalism and expressed $H_{\mathrm{el}}$ $\operatorname{as}^{20}$

$$
H_{\mathrm{el}}=\frac{m_{\mathrm{ij}} \Delta E_{\mathrm{ij}}}{\sqrt{\left(\Delta \mu_{\mathrm{ij}}\right)^{2}+4\left(m_{\mathrm{ij}}\right)^{2}}}
$$

where $\Delta E_{\mathrm{ij}}$ is the energy gap between the initial adiabatic state and the final one, $\Delta \mu_{\mathrm{ij}}$ is the difference in dipole moment between state $\mathrm{i}$ and state $\mathrm{j}$, and $m_{\mathrm{ij}}$ is the transition dipole moment connecting the two states. In this study, the transition energy and the transition dipole moment were calculated by TD-DFT with the $6-31 \mathrm{G}^{*}$ basis set. The dipole moment of excited states can be calculated by a finite field strategy $(0.001$ $\mathrm{au}$ for the field factor) according to Hellmann-Feynman 
A

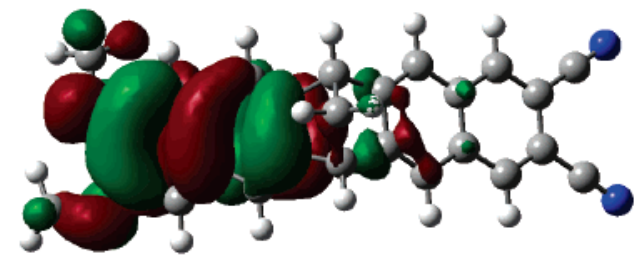

HOMO

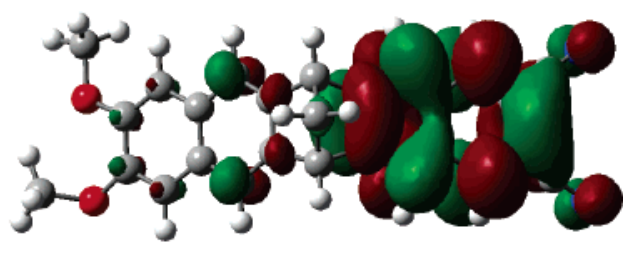

LUMO

B

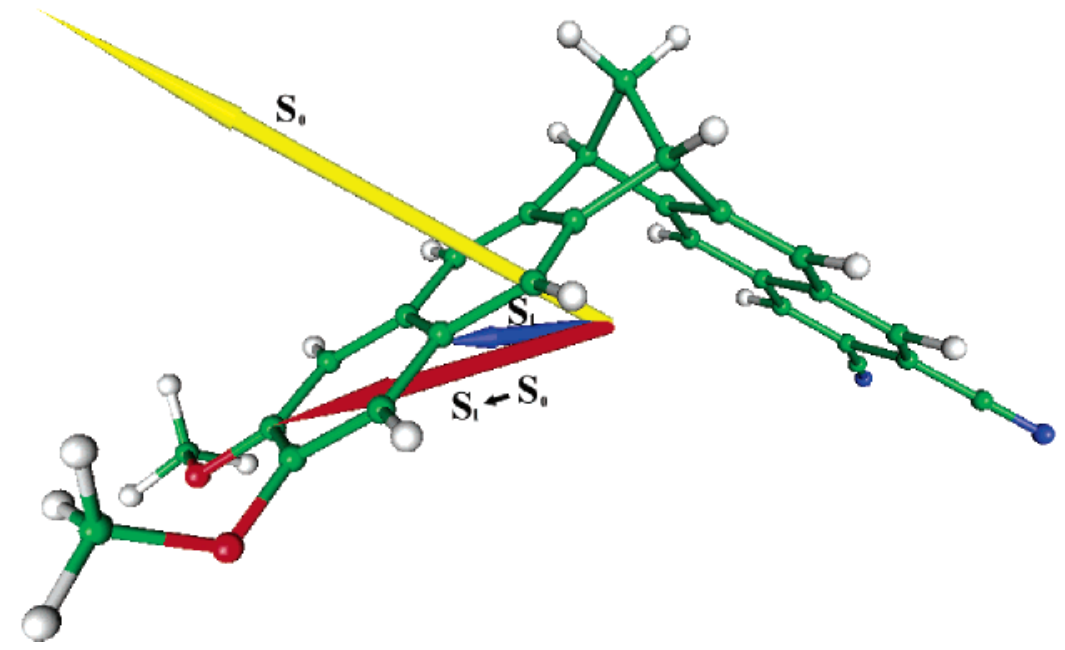

Figure 9. Calculated (A) frontier orbitals and (B) vectors of the associated dipole moment in both ground (11.5 D) and first singlet cited state (3.59 D) as well as the $S_{0} \rightarrow S_{1}$ transition moment $(0.11 \mathrm{D}$, enlarged 50 times in the figure) for compound $\mathbf{I}$.

theory, ${ }^{21}$ in which the dipole moment is the analytic derivative of the energy of the excited state with respect to an applied electric field. Figure 9B depicts the calculated vectors of the associated dipole moment in both the ground and the first singlet excited state as well as the corresponding magnitudes. According to eq $9,\left|H_{\mathrm{el}}\right|$ was calculated to be $860 \mathrm{~cm}^{-1}$ for $\mathbf{I}$, which is apparently much greater than the thermal energy at $298 \mathrm{~K}(\sim 200$ $\mathrm{cm}^{-1}$ ). This, in combination with experimentally resolved 21.9 and $3.2 \mathrm{~cm}^{-1}$ for $\mathbf{I}$ and $\mathbf{I I}$, respectively, firmly supports the switching mechanism from the adiabatic (I) to the nonadiabatic (II, III) electron-transfer process.

\section{Conclusion}

In conclusion, a new series of dyads systems bearing $\mathrm{D}$ (dimethoxynaphthalene)/A (dicyanonaphthalene) derivatives render an excellent model to demonstrate the $\sigma$-bond distance tuning electron-transfer process from an adiabatic (I) to a nonadiabatic (II and III) process. The tendency of the coupling magnitude is consistent with the experimental observation, in which system I, owing to its strong D/A coupling $\left(\left|H_{\mathrm{el}}\right| \sim 860\right.$ $\mathrm{cm}^{-1}$ ), essentially undergoes an adiabatic type of optical transfer, resulting in a unique charge-transfer emission being subject to remarkable solvatochromism. Conversely, due to small electronic coupling of $\left|H_{\mathrm{el}}\right|$ for systems II $\left(21.9 \mathrm{~cm}^{-1}\right)$ and IIII $(3.2$ $\mathrm{cm}^{-1}$ ), a relatively much slower nonadiabatic electron transfer (i.e., PET) takes place in systems II and III, giving rise to dual emission in certain polar solvents. $k_{\mathrm{et}}$ in II is apparently much faster than that of III in the same solvent (see Table 1), consistent with many bridge-distance-tuning PET formulisms. ${ }^{22}$

For systems II and III, values of $k_{\text {et }}$ show weak dependence as a function of the solvent polarity. This is expected for a forward electron-transfer process, in which the generation of a charge-separated state is from an initially neutral species. In contrast, due to the generation of a neutral species via a chargeseparated state, dramatic polarity effects on the excited ET state $\rightarrow \mathrm{S}_{0}$ back-electron-transfer rate and hence the quenching of fluorescence of the ET emission are predicted. This has been shown as a lack of ET emission for III in $\mathrm{CH}_{3} \mathrm{CN}$ due to the exceedingly long radiative lifetime.

From the fundamental viewpoint, results should attract theoretical attention toward the differentiation between adiabatic and nonadiabatic electron transfer tuned by either subtle changes of the D/A distance or a strategic design of the D/A chromophores. It is worth noting that through the pulse radiolysis of a series of 1,4-dimethoxynaphthalene (D) - bridge-1,1dicyanoethylene (A) systems, Paddon-Row and co-workers ${ }^{22 a b}$ were able to differentiate the optical transfer from the thermal electron transfer in a semiquantitative manner. The corresponding ultraweak electron-transfer emission, however, impedes detailed investigation on spectroscopic and relaxation dynamics. For the current applied systems, the adiabatic, allowed transition for I leads to an emission quantum yield of as large as $>0.1$ in all the solvents studied (see Table 1). Moreover, the distinct dual emission in II and III makes comprehensive temperature- 
dependent studies possible, and hence the electronic coupling term has been precisely deduced. We thus present an excellent model to clearly demonstrate the switch in the electron-transfer reaction from adiabatic to nonadiabatic types.

Acknowledgment. We thank the National Science Council (grant number 99-1989-2004) for financial support and the National Center for High Performance Computing.

Supporting Information Available: Detailed characterization of compounds I-III, equations for solvent-polaritydependent studies and photoinduced electron transfer. This material is available free of charge via the Internet at http:// pubs.acs.org.

\section{References and Notes}

(1) (a) Balzani. V. Electron Transfer in Chemistry; Wiley-VCH Weinheim, New York, 2001. (b) Kuznetsov, A. M.; Ulstrup, J. Electron Transfer in Chemistry and Biology: An Introduction to the Theory; John Wiley: New York, 1999. (c) Astruc, D. Electron Transfer and Radical Processes in Transition Metal Chemistry; VCH: New York, 1995. (d) Jortner, J.; Bixon, M. Electron Transfer: From Isolated Molecules to Biomolecules. Part 1; Wiley: New York, 1999. (e) Mattay. J. Electron Transfer II; Springer: New York, 1996. (f) Johnson, M. K. Electron Transfer in Biology and the Solid State: Inorganic Compounds with Unusual Properties; American Chemical Society: Washington, DC, 1990. (g) Bolton, J. R.; Mataga, N.; McLendon, G. Electron Transfer in Inorganic, Organic, and Biological Systems; American Chemical Society: Washington, DC, and Canadian Society for Chemistry: Ottawa, Canada, 1991. (h) Klessinger, M. Excited States and Photochemistry of Organic Molecules; VCH: New York, 1995. (i) Lever, A. B. P. Excited States and Reactive Intermediates: Photochemistry, Photophysics, and Electrochemistry; American Chemical Society: Washington, DC, 1986. (j) Speiser, S. Chem. Rev. 1996, 96, 19531976. (k) Wasielewski, M. Chem. Rev. 1992, 92, 435. (1) Turro, N. J.; Kavarnos, G. J. Chem. Rev. 1986, 86, 401-449. (m) Grabowski, Z. R. Rotkiewicz, K.; Rettig, W. Chem. Rev. 2003, 103, 3899-4032. (n) Yoshihara, T.; Druzhinin, S. I.; Zachariasse, K. A. J. Am. Chem. Soc. 2004 $126,8535-8539$.

(2) (a) Ritchie, J. E.; Murray, R. W. J. Am. Chem. Soc. 2000, 122 2964-2965. (b) Nelsen, S. F.; Ismagilov, R. F.; Powell, D. R. J. Am. Chem Soc. 1998, 120, 1924-1925. (c) Creutz, C. Inorg. Chem. 1978, 17, 37233725. (d) Ranganathan, S.; Murray, R. W. J. Phys. Chem. B 2004, 108 , 19982-19989. (e) Hupp, J. T.; Weydert, J. Inorg. Chem. 1987, 26, 26572660. (f) Dinolfo, P. H.; Williams, M. E.; Stern, C. L.; Hupp, J. T. J. Am. Chem. Soc. 2004, 126, 12989-13001. (g) Ammon, U.; Chiorboli, C.; Dumler, W.; Grampp, G.; Scandola, F.; Kisch, H. J. Phys. Chem. A 1997, 101, 6876-6882. (h) Blackbourn, R. L.; Dong, Y.; Lyon, L. A.; Hupp, J. T. Inorg. Chem. 1994, 33, 4446-4452. (i) Brunschwig, B. S.; Ehrenson, S.; Sutin, N. J. Phys. Chem. 1987, 91, 4714-4723. (j) Elliott, C. M.; Derr, D. L.; Matyushov, D. V.; Newton, M. D. J. Am. Chem. Soc. 1998, 120, 11714-11726. (k) Penfield, K. W.; Miller, J. R.; Paddon-Row, M. N.; Cotsaris, E.; Oliver, A. M.; Hush, N. S. J. Am. Chem. Soc. 1987, 109, 50615065. (1) Mever, T. J. Acc. Chem. Res. 1978, 11, 94-100. (m) Hupp, J. T. Neyhart, G. A.; Meyer, T. J.; Kober, E. M. J. Phys. Chem. 1992, 96, $10820-$ 10830. (n) Powers, M. J.; Meyer, T. J. J. Am. Chem. Soc. 1980, 102, 2 , 1289-1297. (o) Brunschwig, B. S.; Ehrenson, S.; Sutin, N. J. Phys. Chem. 1986, $90,3657-3668$

(3) (a) Oevering, H.; Paddon-Row, M. N.; Heppener, M.; Oliver, A. M.; Cotsaris, E.; Verhoeven, J. W.; Hush, N. S. J. Am. Chem. Soc. 1987 109, 3258-3269. (b) Warrener, R. N.; Pitt, I. G.; Butler. D. N. Chem. Commun. 1983, 1340-1342. (c) Closs, G. L.; Calcaterra, L. T.; Green, N. J.; Penfield, K. W.; Miller, J. R. J. Phys. Chem. 1986, 90, 3673-3683. (d) Warrener, R. N.; Abbenante, G.; Kennard, C. H. L. J. Am. Chem. Soc. 1994, 116, 3645-3646.

(4) (a) Matyushov, D. V.; Voth, G. A. J. Phys. Chem. A. 1999, 103, 10981-10992. (b) Kosower, E. M.; Kanety, H.; Dodiuk, H.; Striker, G.; Jovin, T.; Boni, H.; Huppert. D. J. Phys. Chem. 1983, 87, 2479-2484. (c) Kometani, N.; Kajimoto, O.; Hara, K. J. Phys. Chem. A. 1997, 101, 49164921. (d) Sparpaglione, M.; Mukamel, S. J. Phys. Chem. 1987, 91, 3938 3943.

(5) (a) Arnold, D. R.; Trecker, D. J.; Whipple, E. B. J. Am. Chem. Soc. 1965, 87, 2596. (b) Feldman, K. S.; Bobo, J. S.; Ensel, S. M.; Lee, Y.
B.; Weinreb, P. H. J. Org. Chem.. 1990, 55, 474. (c) Chen, K.-Y.; Chow, T. J.; Chou, P.-T.; Cheng, Y.-M.; Tsaia, S.-H. Tetrahedron Lett. 2002, 43 , 8115.

(6) (a) Diederich, F.; Gramlich, V.; Herrmann, A.; Ringsdorf, H.; Thilgen, C. Helv. Chim. Acta. 1993, 76, 2445. (b) Mcomie, J. F. W.; Perry, D. H. Synthesis 1973, 416. (c) Chow, T. J.; Pan, Y.-T.; Yeh, Y.-S.; Wen, Y.-S.; Chen, K.-Y.; Chou, P.-T. Tetrahedron 2005, 61, 6967.

(7) (a) Chou, P.-T.; Yu, W.-S.; Cheng, Y.-M.; Pu, S.-C.; Yu, Y.-C.; Lin, Y.-C.; Huang, C.-H.; Chen, C.-T. J. Phys. Chem. A 2004, 108, 6487. (b) Chou, P.-T.; Chen, Y.-C.; Yu, W.-S.; Chou, Y.-H.; Wei, C.-Y.; Cheng, Y.-M. J. Phys. Chem. A 2001, 105, 1731.

(8) (a) Jamorski, C.; Casida, M. E.; Salahub, D. R. J. Chem. Phys. 1996, 104, 5134. (b) Petersilka, M.; Gossmann, U. J.; Gross, E. K. U. Phys. Rev. Lett. 1996, 76, 1212. (c) Bauernschmitt, R.; Ahlrichs, R.; Hennrich, F. H.; Kappes, M. M. J. Am. Chem. Soc. 1998, 120, 5052. (d) Casida, M. E. J. Chem. Phys. 1998, 108, 4439. (e) Stratmann, R. E.; Scuseria, G. E. Frisch, M. J. J. Chem. Phys. 1998, 109, 8218.

(9) (a) Lee, C.; Yang, W.; Parr, R. G. Phys. Rev. B 1988, 37, 785. (b) Becke, A. D. J. Chem. Phys. 1993, 98, 5648.

(10) Yu, J.-K.; Cheng, Y.-M.; Hu, Y.-H.; Chou, P.-T.; Chen, Y.-L.; Lee, S.-W.; Chi, Y. J. Phys. Chem. B 2004, 108, 19908.

(11) (a) Scholes, G. D.; Ghiggino, K. P.; Oliver, A. M.; Paddon-Row, M. N. J. Am. Chem. Soc. 1993, 115, 4345-4349. (b) Scholes, G. D.; Turner, G. O.; Ghiggino, K. P.; Paddon-Row, M. N.; Piet, J. J.; Schuddeboom, W.; Warman, J. M. Chem. Phys. Lett. 1998, 292, 601-606.

(12) Shynkar, V. V.; Mély, Y.; Duportail, G.; Piémont, E.; Klymchenko, A. S.; Demchenko, A. P. J. Phys. Chem. A 2003, 107, 9522-9529.

(13) (a) Gosavi, S.; Marcus, R. A. J. Phys. Chem. B 2000, 104, 20672072. (b) Marcus. R. A. J. Phys. Chem. 1990, 94, 4152-4155. (c) Siddarth, P.; Marcus. R. A. J. Phys. Chem. 1992, 96, 3213-3217. (d) Marcus. R. A. J. Phys. Chem. 1991, 95, 2010-2013. (e) Marcus. R. A. J. Phys. Chem. 1992, 96, 1753-1757. (f) Marcus, R. A.; Almeida, R. J. Phys. Chem. 1990 94, 2973-2977. (g) Siders, P.; Marcus, R. A. J. Am. Chem. Soc. 1981, 103, 3, 748-752. (h) Siddarth, P.; Marcus, R. A. J. Phys. Chem. 1990, 94, 8430-8434. (i) Marcus, R. A. J. Phys. Chem. 1990, 94, 1050-1055. (j) Marcus, R. A. J. Phys. Chem. B 1998, 102, 10071-10077. (k) Siders, P.; Marcus, R. A. J. Am. Chem. Soc. 1981, 103, 741-747. (1) Tanaka, S.; Marcus, R. A. J. Phys. Chem. B 1997, 101, 5031-5045. (m) Marcus, R. A.; Siders, P. J. Phys. Chem. 1982, 86, 622-630.

(14) Lide, D. R., ed. CRC Handbook of Chemistry and Physics, 74th ed.; CRC Press: Boca Raton, FL, 1993.

(15) Chou, P. T.; Chang, C. P.; Clements, J. H.; Kuo, M. S. J. Fluorescence 1995, 5, 369-375.

(16) (a) Hopfield, J. J. In Protein Structure: Molecular and Electronic Reactivity; Springer: New York, 1987. (b) Joran, A. D.; Leland, B. A.; Felker, P. M.; Zewail, A. H.; Hopfield, J. J.; Dervan, P. B. Nature (London) 1987, 327, 508-511

(17) Kang, T. J.; Kahlow, M. A.; Giser, D.; Swallen, S.; Nagarajan, V.; Jarzeba, W.; Barbara, P. F. J. Phys. Chem. 1988, 92, 6800-6807.

(18) (a) Mulliken. R. S. J. Phys. Chem. 1952, 56, 801-822. (b) Mulliken, R. S. Chem. Rev. 1947, 41, 201-206. (c) Hush, N. S.; Wong, A. T.; Bacskay, G. B.; Reimers, J. R. J. Am. Chem. Soc. 1990, 112, 4192-4197. (d) Penfield, K. W.; Miller, J. R.; Paddon-Row, M. N.; Cotsaris, E.; Oliver, A. M.; Hush. N. S. J. Am. Chem. Soc. 1987, 109, 5061-5065. (e) Mulliken, R. S.; Ermler, W. C. Diatomic Molecules: Results of ab Initio Calculations; Academic Press: New York, 1977.

(19) (a) Cave, R. J.; Newton, M. D.; Kumar, K.; Zimmt. M. B. J. Phys Chem. 1995, 99, 17501-17504. (b) Miller, N. E.; Wander, M. C.; Cave, R. J. J. Phys. Chem. A 1999, 103, 1084-1093. (c) Rust, M.; Lappe, J.; Cave, R. J. J. Phys. Chem. A 2002, 106, 3930-3940.

(20) (a) He, R.-X.; Duan, X.-H.; Li, X.-Y. J. Phys. Chem. A 2005, 109 4154-4161. (b) Cave, R. J.; Newton, M. D. Chem. Phys. Lett. 1996, 249, $15-19$.

(21) (a) Hellmann, H. Einfuhrung in die Quantenchemie; F. Deuticke: Leipzig, 1937. (b) Feynman, R. P. Phys. Rev. 1939, 56, 340.

(22) (a) Penfield, K. W.; Miller, J. R.; Paddon-Row, M. N.; Cotsaris, E.; Oliver, A. M.; Hush, N. S. J. Am. Chem. Soc. 1987, 109, 5061-5065. (b) Oevering, H.; Paddon-Row, M. N.; Heppener, M.; Oliver, A. M.; Cotsaris, E.; Verhoeven, J. W.; Hush, N. S. J. Am. Chem. Soc. 1987, 109, 3258-3269. (c) McConnell, H. M. J. Chem. Phys. 1961, 35, 508-515. (d) Paddon-Row, M. N. Acc. Chem. Res. 1994, 27, 18-25. (e) Black, A. J.; Wooster, T. T.; Geiger, W. E.; Paddon-Row, M. N. J. Am. Chem. Soc. 1993, 115, 7924-7925. 